\title{
ASYMMETRIC CELLULOSE ACETATE MEMBRANES USED IN SEPARATION APPLICATIONS
}

\author{
Gabriela CIOBANU ${ }^{1}$, Lidia FAVIER ${ }^{2}$, Maria HARJA ${ }^{1}$ \\ *E-mail: gciobanu@tuiasi.ro
}

Received: Mar. 12, 2021. Revised: Mar. 22, 2021 Accepted: Mar. 26, 2021. Published online: Mar. 31, 2021

\begin{abstract}
This work focused on the use of cellulose acetate polymer for the preparation of porous asymmetric membranes using a phase inversion process. These membranes were characterised by scanning electron microscopy, a bubble-point method and sorption measurements. The preparation method used induced membrane anisotropy. The capacity of the membranes in the removal of electrolyte $(\mathrm{NaCl})$ from aqueous solution was investigated. A good retention of $58.6 \%$ and a high flux rate of $8.9 \times 10^{-4} \mathrm{~m} / \mathrm{s}$ using $\mathrm{NaCl}$ solution of $200 \mathrm{mg} / \mathrm{L}$ concentration were obtained by cellulose acetate membranes prepared with water as non-solvent. The results showed that the membrane performance was affected by the membrane structure, which was determined by the conditions of membrane preparation.
\end{abstract}

Keywords: cellulose acetate polymer; porous membrane; asymmetric structure; salt rejection.

\section{INTRODUCTION}

Membrane processes are a good alternative to conventional water (Ladewig and Al-Shaeli, 2017; Peinemann and Nunes, 2010). Nanofiltration, reverse osmosis, microfiltration, ultrafiltration, etc. are membrane processes currently used to obtain drinking water and in the depollution of wastewater in order to protect the environment. One of the very important applications of membrane filtration is water desalination, i.e., the elimination of salts from seawater, but also the removal of toxic compounds existing in wastewater arising from various industries (Ciobanu et al., 2009; Ciobanu and Carja, 2010; Goh et al., 2016; Elimelech and Phillip, 2011).

Filter membranes, depending on their structure, can be symmetrical or asymmetrical, porous or non-porous.

\footnotetext{
${ }^{1}$ Faculty of Chemical Engineering and Environmental Protection "Cristofor Simionescu”, "Gheorghe Asachi” Technical University of laşi, 73 D. Mangeron Bvd., laşi, 700050, Romania

2 University of Rennes, Ecole Nationale Supérieure de Chimie de Rennes, CNRS, ISCR - UMR6226, F-35000 Rennes, France
} 
Also, depending on the materials from which they are made, the membranes can be polymeric, ceramic or polymer-polymer or polymer-ceramic composites.

A crucial moment in membrane technology was 1962, when Loeb and Sourirajan developed the phase inversion method for obtaining integrally skinned asymmetric membranes (Loeb and Sourirajan, 1962). This method involves the addition of a multicomponent solution (consisting of either a binary mixture of polymer and solvent or a combination of polymers, solvents, and non-solvents) in a coagulation bath (containing a non-solvent immiscible with the polymer). The counter diffusion between solvent and non-solvent leads to a phase instability in the solution, which results in the separation of the wet phase to form a membrane with an asymmetric structure (Ismail and Yean, 2003). The obtained membranes are formed by superimposed layers of different thicknesses and porosities: a top skin layer, a porous sub-layer (substructure) and a bottom skin (Ciobanu and Ciobanu, 2015; Kesting, 1985; Purkait et al., 2018).

In recent years, many studies have focused on the phase inversion process because it is one of the most versatile, economical and reproducible processes for forming polymeric asymmetric membranes (Baldino et al., 2017). In recent years, many categories of polymers with specific properties have been used to obtain asymmetric membranes, which have led to various applications in the separation and purification processes. A very important aspect in the research carried out by the specialists in the membrane science is to obtain membranes with a higher selectivity and high flow (Gao et al., 2011; Huang et al., 2019; Khan et al., 2020). Cellulose acetate is a modified natural polymer with a wide range of properties and applications (e.g., for films, membranes or fibres) (Fischer et al., 2008). Cellulose acetate is used in the preparation of ultra- and nanofiltration membranes for gas or liquid separation applications due to its good hydrophilicity, high toughness, and low price (Idress et al., 2021). The hydrophilic nature of cellulose acetate is desirable in a membrane process: wetting the membrane reduces the internal concentration polarisation (and this reduces membrane fouling) and increases water flux.

This study investigated whether cellulose acetate sheets could be used as semipermeable membranes in water desalination. The membranes were produced by a very easy method based on the phase inversion process. Membrane characterisations, such as morphology and sodium chloride rejection are reported.

\section{EXPERIMENTAL}

\section{Materials}

Cellulose acetate with $39.8 \%$ acetyl content and average molecular weight Mn of $\sim 30,000$, acetone, formamide and $\mathrm{NaCl}$ were purchased from Sigma-Aldrich (Germany). In the coagulation process, 


\section{Gabriela CIOBANU, Lidia Favier, Maria HARJA}

acetone acted as a solvent, while formamide or water acted as non-solvents. In order to evaluate the membrane performance in terms of percentage rejection and flux rate, $\mathrm{NaCl}$ solutions of different concentrations were prepared.

\section{Membrane preparation}

The membranes were prepared via the phase inversion method described elsewhere (Ciobanu and Bezdadea, 2004), starting from a $20 \mathrm{wt} \%$ cellulose acetate solution in acetone. Cellulose acetate and acetone were stirred in an Erlenmeyer flask until a homogeneous solution was formed (20-24 h). A fixed amount of nonsolvent (deionised water or formamide) was added slowly to the polymer solution and stirred for another 2-3 h. The solution was then cast at ambient temperature on a glass dish with a special stainless-steel cast knife. The thickness of the fabricated membrane was $\sim 300-350 \mu \mathrm{m}$. As soon as possible, the thin layer of cast solution together with the glass plate was immersed in the coagulation bath of pure water. The membranes formed were left in the coagulation bath for 30-60 min and then transferred to deionised water until characterisation.

\section{Membrane characterisation}

The sample morphology was investigated by scanning electron microscopy (SEM) with a TESLA-BS300 instrument. The pore sizes were estimated by the bubble-point method with a home-made laboratory instrument.

The permeation experiments were carried out in a dead-end flow cell using circular membranes with a $12.5 \mathrm{~cm}^{2}$ effective area available for filtration. The flux rate and solute rejection were measured using $\mathrm{NaCl}$ solutions of different concentrations, at $25^{\circ} \mathrm{C}$ and at $\sim 5$ bar applied feed pressure. The conductivity of the permeate was measured using a conductivity meter, model CONSORT C831. Parameters used to quantify the membrane performance were flux rate of the solutions $\mathrm{J}(\mathrm{m} / \mathrm{s})$, and salt rejection $\mathrm{R}(\%)$ :

$$
\begin{aligned}
J & =\frac{V}{t \cdot A} \\
R(\%) & =\left[1-\frac{C_{p}}{C_{f}}\right] \cdot 100
\end{aligned}
$$

where, $V / t$ is volume permeation rate $\left(\mathrm{m}^{3} / \mathrm{s}\right), A$ is membrane area $\left(\mathrm{m}^{2}\right)$, and $C_{p}$ and $C_{f}$ are the concentrations of the permeate and feed solutions, respectively.

\section{RESULTS AND DISCUSSION}

Generally, the morphology of a membrane (i.e., thickness or porosity) is influenced by the process parameters, which ultimately lead to certain separation performances of the membrane (Idris et al., 2002; Wang et al., 2006). Phase inversion is a good method for obtaining integrally skinned asymmetric membranes (Loeb and Sourrirajan, 1962; Strathmann et al., 1975; Garcia et al., 2020).

In our study, the obtained microporous membranes (i.e., CAM-F and CAM-W) have an open threedimensional structure in which the pores are of molecular size consisted of a three-dimensional polymeric structure with pore sizes of molecular dimensions, which offer specific permeability to a component in a process feed to the membrane. These membranes have a quite complex, open, colloidal-type structure with a small fraction of the membrane volume occupied by the polymer substrate. The cellulose acetate 
membranes appeared to be a cohesive system consisting of open-cell foams (i.e., vacuoles with branched walls) composed of a cellular network bound together by chainlike ribs extending in three dimensions. The SEM images of the cellulose acetate membranes were evidence of the asymmetry/ heterogeneity of these systems (Fig. 1).

All the membranes have an asymmetric structure consisting of several layered areas, namely: the active layer (an ultra-thin skin layer), the transition layer (an open-cell and finger-like substructure) and the bottom layer. As reported by Kestingm (Kesting, 1985), generally large finger-like macrovoids and cavity-like structures are formed when the coagulation process is rapid, whereas a slow coagulation rate
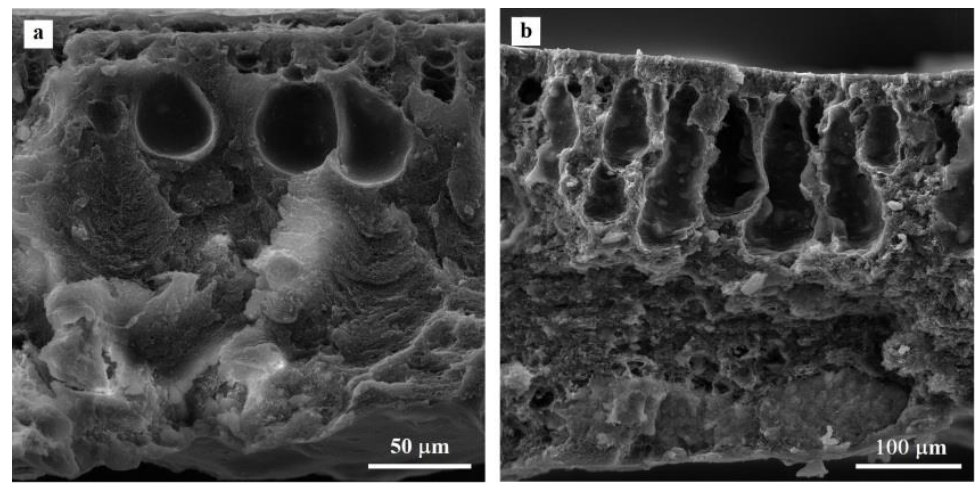

Figure 1 - SEM images of cellulose acetate membranes in cross-section: a) CAM-F and b) CAM-W samples

Table 1 - Physical characteristics of the prepared cellulose acetate membranes

\begin{tabular}{lcc}
\hline Characteristic & CAM-F* & CAM-W* \\
\hline Thickness $(\mu \mathrm{m})$ & 240 & 375 \\
\hline Pore diameter in top surface $(\mu \mathrm{m})$ & $0.2-2.5$ & $0.5-8.5$ \\
\hline Void diameter in substructure $(\mu \mathrm{m})$ & $10-40$ & $15-70$ \\
\hline
\end{tabular}

*The non-solvent was formamide $(F)$ or water $(W)$. 



\section{Gabriela CIOBANU, Lidia Favier, Maria HARJA}

In the first stage of the study, the pure water flux of the membranes was determined. At $25^{\circ} \mathrm{C}$ and 5-bar applied pressure, the pure water fluxes values for CAM-F and CAM-W samples were about $4.5 \times 10^{-4} \mathrm{~m} / \mathrm{s}$ and $5.3 \times 10^{-4} \mathrm{~m} / \mathrm{s}$, respectively, showing that the pure water flux was increased for cellulose acetate membranes prepared with water as non-solvent (CAM-W sample).
In the second step, the capacity of the membranes for electrolyte $(\mathrm{NaCl})$ removal from aqueous solution was investigated. The results, in terms of flux rate $(J)$ and percentage rejection (R\%) are presented in Table 2, showing that the flux and percentage rejection were increased for cellulose acetate membranes obtained by using water as non-solvent (CAM-W sample).

Table 2 - Performance of the prepared cellulose acetate membranes

\begin{tabular}{lcc|cc}
\hline \multirow{3}{*}{ Characteristic } & \multicolumn{3}{c}{ Membrane } \\
\cline { 2 - 5 } & \multicolumn{3}{c}{ CAM-F } & \multicolumn{2}{c}{ CAM-W } \\
\cline { 2 - 5 } & 10 & 200 & 10 & 200 \\
\cline { 2 - 5 } & 7.2 & 7.4 & 5.3 & 8.9 \\
\hline $\mathrm{J}(\mathrm{m} / \mathrm{s}) \times 10^{-4}$ & 49.3 & 51.2 & 58.1 & 58.6 \\
\hline $\mathrm{R} \%(\%)$ & &
\end{tabular}

According to the obtained results it can be observed that the performances of the analysed membranes are influenced by the membrane structure that depends on the conditions of membrane preparation, the composition of the casting solution being very important. During the phase inversion processes, due to some phenomena of microphase separation in the of evaporation and/or quenching of the polymeric solution, the formation of the asymmetric cellulose acetate membrane takes place.

Considering the experimental results, it can be concluded that these asymmetric cellulose acetate membranes can be used in various separation processes, especially for the removal of electrolytes from wastewater.

\section{CONCLUSION}

The membranes tested in this study, were obtained by the phase inversion method having as a precursor cellulose acetate solution (20 wt.\%) in acetone to which a fixed amount of non-solvent (deionised water or formamide) was added. The obtained membranes consist of several layered areas, namely: the active layer (an ultra-thin skin layer), the transition layer (an open-cell and finger-like substructure) and the bottom layer. The experimental results demonstrated that the membrane's properties were influenced of its structure, which was determined by the membrane preparation conditions, i.e., the nature of the non-solvent in the casting solution. 


\section{ASYMMETRIC CELLULOSE ACETATE MEMBRANES USED IN SEPARATION APPLICATIONS}

The ternary system: cellulose acetate-acetone - water, used in this study, determined obtaining of new membrane on the base of cellulose acetate that can be successfully used for a water desalination process. Tested membranes showed a proper pure water flux and a moderate percentage of rejection using a $\mathrm{NaCl}$ solution of $200 \mathrm{mg} / \mathrm{L}$ concentration.

\section{REFERENCES}

Baldino, L., Cardea, S. \& Reverchon, E. (2017). Biodegradable membranes loaded with curcumin to be used as engineered independent devices in active packaging. J. Taiwan Inst.Chem.Eng., 71: 518-526, DOI: 10.1016/j.jtice.2016.12.020

Ciobanu, M.G. \& Bezdadea, M. (2004). SAPO-5 zeolite-filled polyurethane membranes. 1. Preparation and morphological characterisation. Rev. Chim., 55(3): 140-143, https://revistadechimie.ro/Articles.as p? ID =301

Ciobanu, G., Ignat, D., Carja, G. \& Luca C. (2009).

Hydroxyapatite/polyurethane composite membranes for lead ions removal. Environ.Eng.Manag.J., 8(6): 1347-1350, https://eemj.eu/ index.php/EEMJ/article/view/2679

Ciobanu, G. \& Carja, G. (2010). Electrolyte removal by mixed matrix membranes based on polyurethane. Desalination, 250 (1-3): 698-701, DOI: 10.1016/j.desal.2009.05.023

Ciobanu, G. \& O Ciobanu, O. (2015). Mixed-matrix membranes based on polyurethane containing nanohydroxyapatite and its potential applications. J.Appl.Polym.Sci., 132(17): 41813, DOI: 10.1002/app. 41813

Elimelech, M. \& Phillip, W.A. (2011). The future of seawater desalination: energy, technology, and the environment. Science, 333: 712-717, DOI: 10.1126/science. 1200488

Fischer, S., Thümmler, K., Volkert, B. \& Hettrich, K. (2008). Properties and applications of cellulose acetate. Macromol.Symp., 262(1): 89-96, DOI: $10.1002 /$ masy.200850210

Gao, W., Liang, H., Ma, J., Han, M., Chen, Z.I., Han, Z.S. \& Li, G.B. (2011), Membrane fouling control in ultrafiltration technology for drinking water production: A review. Desalination, 272: 1-8, DOI: 10.1016/j.desal.2011.01.051

Garcia, J.U., Iwama, T., Chan, E.Y., Tree, D.R., Delaney, K.T. \& Fredrickson, G.H. (2020). Mechanisms of asymmetric membrane formation in nonsolventinduced phase separation. ACS Macro. Lett., 9(11): 1617-1624, DOI: 10.1021/acsmacrolett.0c00609

Goh, P., Matsuura, T., Ismail, A. \& Hilal, N. (2016). Recent trends in membranes and membrane processes for desalination. Desalination, 391: 43-60, DOI : 10.1016/i.desal.2015.12.016

Huang, T.F., Puspasari, T., Nunes, S.P. \& Peinemann, K.V. (2019). Ultrathin 2D-layered cyclodextrin membranes for high-performance organic solvent nanofiltration. Adv.Funct.Mater., 30(4): 1906797, DOI: 10.1002/adfm.201906797

Idress, H., Zaidi, S.Z.J., Sabir, A., Shafiq, M., Khan, R.U., Harito, C., Hassan, S. \& Walsh, F.C. (2021). Cellulose acetate based complexation-NF membranes for the removal of $\mathrm{Pb}$ (II) from waste water. Sci.Rep., 11: 1806, DOI: 10.1038/s41598-020-80384-0

Idris, A., Ismail, A.F., Noorhayati, M. \& Shilton, S.J. (2002). Measurement of rheologically induced molecular orientation using attenuated total reflection infrared dichroism in reverse osmosis hollow fiber cellulose acetate membrane and influence on separation 


\section{Gabriela CIOBANU, Lidia Favier, Maria HARJA}

performance. J.Membr.Sci., 213: 4554, DOI: 10.1016/S0376-7388(02) 00511-2

Ismail, A.F. \& Yean, L.P. (2003). Review on the development of defect-free and ultrathin-skinned asymmetric membranes for gas separation through manipulation of phase inversion and rheological factors, J.Appl.Polym.Sci., 88: 442-451, 10.1002/app.11744

Kesting, R.E. (1985). Synthetic polymeric membranes: a structural perspective. 2nd Edition, Wiley-Interscience, New York.

Khan, U., Biccai, S., Boland, C.S. \& Coleman, J.N. (2020). Low cost, high performance ultrafiltration membranes from glass fiber-PTFEgraphene composites. Sci.Rep., 10: 21123, DOI: 10.1038/s41598-02078091-x

Ladewig, B. \& Al-Shaeli, M.N.Z. (2017). Fundamentals of membrane processes. In: Fundamentals of membrane bioreactors. Springer Transactions in Civil and Environmental Engineering, Springer, Singapore, DOI: 10.1007/978-98110-2014-8_ 2

Loeb, S. \& Sourirajan, S. (1962). Sea water demineralization by means of an osmotic membrane, Chapter 9. In: Saline Water Conversion II. Gould, R.F. (Ed.), ACS Symp.Ser. Am.Chem.Soc., 38: 117-132, DOI: 10.1021/ba-1963-0038.ch009

Peinemann, K.V. \& Nunes, S.P. (2010). Membranes for water treatment, Volume 4. In: Membrane Technology, Wiley, Weinheim, DOI: 10.1002/9783527631407

Purkait, M.K., Sinha, M.K., Mondal, P. \& Singh, R. (2018). Introduction to Membranes, Chapter 1. In: Interface Science and Technology, Vol. 25, Elsevier, London, pp. 1-37, DOI: 10.1016/B978-0-12-8139615.00001-2

Strathmann, H., Kock, K., Amar, P. \& Baker, R.W. (1975). The formation mechanism of asymmetric membranes. Desalination, 16(2): 179-203, DOI: 10.1016/S0011-9164 (00)82092-5

Wang, M., Wu, L. \& Gao C. (2006). The influence of phase inversion process modified by chemical reaction on membrane properties and morphology. J.Membr.Sci., 270(1-2): 154-161, DOI: 10.1016/j.memsci.20 05.06.051 